\section{Production Chemicals for the Oil and Gas Industry}

by Malcolm A. Kelland: CRC Press, Boca Raton, Fl, USA, 2009, pp 400, ISBN 978-1-4200-9290-5, Price: GBP 78.99, USD 129.95

A great deal of money is spent on chemicals by the oil industry in the various applications described in this book but it must be remembered that a $1 \%$ increase in yield of a field could represent many extra billions of income to its operator. A second general point why this is important is that, despite the current frenetic search for sustainable sources of energy, the world is still going to be largely dependent on oil and oil products for many years to come. This book differs from many texts in that the author deals less with the performance of various chemicals for specific tasks but rather on the structures that are known to deliver the required performance; this approach makes it more useful to those concerned with research and development.

Chemicals of various kinds are used to aid the production of oil and gas from the drilling of the well, through to the separation plant so that the crude oil is in a suitable condition for transfer via a pipeline or tanker to the tank farm of the refinery. With the strict laws on the quality of water discharged into the sea, the use of suitable chemicals is of increasing concern for production chemists. In 17 chapters this book explains in considerable detail how, when, where and why these chemicals are used. The first chapter entitled "Introduction and Environmental Issues" is an excellent overview of the types of problems faced by production chemists. The subjects covered include problems caused by fouling of tanks and lines due to the precipitation of wax and asphaltenes; the formation of foams and emulsions and water removal; corrosion in pipelines and storage vessels; environmental concerns such as oily water treatment and the presence of sulfur compounds, particularly $\mathrm{H}_{2} \mathrm{~S}$ which is toxic at ppm levels. Environmental matters are dealt with in detail and include Environmental Regulations for Oilfield Chemicals Specific to the NE Atlantic and the North Sea (SPAR); The European "Reach" Regulations; those for the USA and finally Offshore Regulations for Norway (ECOTOX).

Each chapter deals with a specific topic, for example Chapter 3 deals with Scale Control that can be the single biggest operational cost in the use of production chemicals. The deposition of scale comes from aqueous solutions of salts, metal ions of organic carboxylates and naphthenes. These deposits can cause reduction of oil production by blocking the pore throats in the near well region and the fouling of pumps downhole. Deposits can be found all along the production train and the most suitable chemicals must be found to inhibit the formation of these deposits. The rest of this chapter deals with the different types of scales and mixtures of scales. The way chemicals are used to prevent the laying down of deposits is explained. This chapter alone takes 38 pages to cover this complex topic and, like the other chapters, it is followed by an extensive list of references.

Another subject deal with in detail is the use of biocides to prevent bacteria reducing sulfur compounds to $\mathrm{H}_{2} \mathrm{~S}$ which is corrosive and a toxic hazard for drilling, production and refinery operators. The formulation of drilling fluids and the special cements for fixing the well casing in situ are not covered since these are nearly always services supplied by specialist contractors. However, a brief summary of these two topics would have been a useful source of information for trainee production chemists.

To summarise, this book covers the multitude of problems facing the production chemist in the oil industry but it is very readable for such a technical subject. It is fine reference book for experienced personnel and an excellent source of information for newcomers.

E. J. Vase 